\title{
Screening for cognitive impairment among individuals aged 60 years or over: scoping review
}

\author{
Patrícia Regina Piedade Feichtenberger', Maura Regina Laureano Rocha", Maria Eduarda dos Santos Puga"', \\ José Eduardo Martinez ${ }^{\text {IV }}$
}

Pontifícia Universidade Católica de São Paulo (PUC-SP), Sorocaba (SP), Brazil

'MD. Neurologist and Master's Degree Student, Pontifícia Universidade Católica de São Paulo (PUC-SP), Sorocaba (SP), Brazil.

(D) https://orcid.org/0000-0002-5104-3620

"MD, PhD. Speech Therapist, Audiology Specialist and Technical director, FONEC - Fonoaudiologia e Neurociência, Itapetininga (SP), Brazil.

(D) https://orcid.org/0000-0002-2342-7555

'"MD, PhD. Librarian, Information specialist at Cochrane Center in Brazil, São Paulo (SP), Brazil; and Director, Library Network, Universidade Federal de São Paulo (UNIFESP), São Paulo (SP), Brazil.

(D) https://orcid.org/0000-0001-8470-861X

"MD, PhD. Rheumatologist and Full Professor, Department of Internal Medicine, Pontifícia Universidade Católica de São Paulo (PUC-SP), Sorocaba (SP), Brazil.

(D) https://orcid.org/0000-0002-3864-6822

KEY WORDS (MeSH terms):

Cognitive dysfunction

Mass screening.

Aged.

Dementia.

Cognition

\section{AUTHORS' KEY WORDS:}

Primary care.

Elderly.

Cognitive impairment.

\begin{abstract}
BACKGROUND: Growth in aging of the population has led to increasing numbers of elderly people presenting cognitive impairment and evolution to dementia. There is still no consensus within primary care on the best strategy for screening for cognitive impairment among elderly people. Standardization of a simple but reasonably accurate instrument for a brief cognitive test, in primary care environments, would enable healthcare professionals to identify individuals who require a more in-depth assessment of cognition.

OBJECTIVES:To investigate the instruments used by healthcare professionals in studies conducted worldwide and ascertain the most suitable instruments for screening for cognitive impairment among individuals aged 60 years or over, in the Brazilian population.

DESIGN AND SETTING: Scoping review developed at Pontifícia Universidade Católica de São Paulo, Brazil. METHOD: A systematic search of the literature was conducted for primary studies using instruments to screen for cognitive impairment among individuals aged 60 years or over, in the MEDLINE, EMBASE, Cochrane Central and LILACS databases.

RESULTS: A total of 983 articles were identified by two independent reviewers, from which 49 were selected for full-text reading, based on the criteria defined for this review. From this, 16 articles adhering to the theme of screening for cognitive impairment among the elderly were selected for in-depth analysis. CONCLUSION: The Mini-Mental State Examination was the instrument most cited in these studies. The Pfeffer Functional Activities Questionnaire and the Verbal Fluency Test (semantic category) present characteristics favoring further studies, for testing as screening instruments for cognitive impairment among elderly people in Brazil.
\end{abstract}

\section{INTRODUCTION}

Although substantial increases in the numbers of elderly people are now foreseen in all countries, greater growth is expected in developing regions such as Brazil, where the proportions are expected to become $18.8 \%$ in 2020 and $29.3 \%$ in $2050 .^{1,2}$

Primary care is considered to be the front line for healthcare for the elderly and can provide regular contacts focused on preventing disabilities resulting from chronic health conditions, such as classification of cognitive impairment in this age group. ${ }^{3}$

Healthcare professionals are faced with the challenge of evaluating the limit of normality among elderly people's cognitive alterations. Within the concept of senescence, they need to differentiate the expected changes for this age group from the pathological conditions of aging that constitute senility. If such conditions are seen at the prodromal stage, reversal or mitigation may still be possible. ${ }^{4,5}$

Development of dementia in elderly people is a measurable risk. Thus, the pathological transition to this, from a mild stage of cognitive impairment, forms a "gray zone" between normality and initial dementia. ${ }^{4}$

Screening for cognitive impairment among elderly people can be achieved through instruments that have already been translated and validated for application in Brazil. ${ }^{6}$

Bustamante et al. ${ }^{7}$ suggested that cognitive tests and functional scales should be used in combination, in populations with educational heterogeneity. This would improve the accuracy of cognitive screening among mild to moderate cases of dementia because, when used together, they 
bring more information than when used separately. The functional scales of questionnaires are less influenced by the interviewee's age, education level or other sociocultural factors. ${ }^{7}$

So far, there is no consensus regarding the best strategy within primary care for screening for cognitive impairment among elderly patients. However, several brief instruments for screening for cognitive impairment have been recommended. ${ }^{8,9}$

No specific drug therapy for treating mild cognitive impairment (MCI) is currently approved. Nonetheless, it was recommended through the FINGER (Finnish Intervention Study to Prevent Cognitive Decline and Disability) study that healthy lifestyle factors such as leisure activities, social interaction, cognitive stimulation, Mediterranean diet and regular physical activity, both for elderly people in general and for those with MCI, should be encouraged as possible protectors against neurodegenerative diseases of aging. ${ }^{10}$

Most individuals and their caregivers would rather know about a diagnosis of dementia as early as possible. This knowledge allows such individuals to make decisions regarding future plans while they still have the ability to do so. ${ }^{11,12}$

In Brazil, around $75 \%$ of the population receives its medical care through the public healthcare system (Sistema Único de Saúde, SUS). In this, care is centered on general practitioners, who play an increasingly important role in screening for cognitive impairment among elderly people, which is often neglected within primary care. Moreover, many primary care providers have difficulty in diagnosing dementia accurately. Particularly at the mild stage, dementia is poorly recognized. ${ }^{13,14}$

Thus, instruments for cognitive screening that are quick to apply but relatively accurate are needed, so that healthcare professionals working within primary care can identify individuals who may require a more in-depth evaluation of cognition, at an early stage, and refer them to secondary care. ${ }^{15}$

The present study consisted of a scoping review, in which instruments for screening for cognitive impairment that have been used in studies in the literature, as applicable to individuals aged 60 years or over, were assessed.

\section{OBJECTIVES}

To investigate the cognitive screening instruments used by healthcare professionals in studies conducted worldwide and ascertain which of these are most suitable for use in screening for cognitive impairment among individuals aged 60 years or over, in the Brazilian population.

\section{METHODS}

The PICO technique (Population, Intervention, Comparison, Outcome) was used to define the question and the development of the research, as follows:
P: Population aged 60 years or over.

I: Use of a screening instrument for cognitive impairment in this population.

C: Comparison between screening instruments for cognitive impairment in this population.

O: Verification of the most suitable instruments for screening for cognitive impairment among elderly people, in the Brazilian population.

\section{Design}

This study consisted of a scoping review of the literature. It was conducted in accordance with the Preferred Reporting Items for Systematic Reviews and Meta-Analyses (PRISMA) methodology. ${ }^{16}$

\section{Search strategy}

The searches were conducted in June 2020 in following databases: MEDLINE (Medical Literature Analysis and Retrieval System Online); EMBASE (Excerpta Medica Database); Cochrane Library; and LILACS (Literatura Latino-Americana e do Caribe em Ciências da Saúde).

The descriptors were chosen and identified in accordance with the Medical Subject Heading (MeSH) and Descritores em Ciências da Saúde (DeCS) lists of descriptors, as follows: cognitive dysfunction; mass screening; and elderly.

The same search strategies were used in all databases. The search was refined by specifying randomized clinical trial (RCT) and the elderly age group, or studies that included individuals aged 60 years or over, depending on the filter for searching the information sources for articles, as described in Table 1. No limit was placed on the date of publication or the languages of these documents. For cases in which an update was found, the latest version was considered.

\section{Criteria for inclusion in the scoping review}

We only included studies that met the following criteria: randomized clinical trials (RCTs) that had been duly registered or observational studies with random sampling; individuals aged 60 years or over who had been recruited from the general population or from primary healthcare attendees, for random sampling, with absence of any reports of presence of pathological conditions or previous treatments; and application of instruments for screening for cognitive impairment and their implications and results. We considered any outcomes that had been assessed and reported by the original authors.

\section{Selection of studies}

The selection process was performed by two authors (MRLR, PRPF), who independently screened all titles and abstracts that had been found through the electronic search. These authors checked their eligibility in relation to the inclusion criteria. 
((“Cognitive Dysfunction”[Mesh] OR (cognitive dysfunctions) OR (dysfunction, cognitive) OR (dysfunctions, cognitive) OR (cognitive impairments) OR (cognitive impairment) OR (impairment, cognitive) OR (impairments, cognitive) OR (mild cognitive impairment) OR (cognitive impairment, mild) OR (cognitive impairments, mild) OR (impairment, mild cognitive) OR (impairments, mild cognitive) OR (mild cognitive impairments) OR (mild neurocognitive disorder) OR (disorder, MEDLINE mild neurocognitive) OR (disorders, mild neurocognitive) OR (mild neurocognitive disorder) OR (neurocognitive disorder, mild) OR (eurocognitive disorders, mild) OR (cognitive decline) OR (cognitive declines) OR (decline, cognitive) OR (declines, cognitive) OR (mental deterioration) OR (deterioration, mental) OR (deteriorations, mental) OR (mental deteriorations))) AND ("Mass Screening"[Mesh] OR (mass screenings) OR (screening, mass) OR (screenings, mass) OR Screening*) Filters: Randomized Controlled Trial, Humans, Middle Aged + Aged: 45+ years, Middle Aged: 45-64 years, Aged: $65+$ years, 80 and over: $80+$ years

(('cognitive dysfunction' OR 'cognitive dysfunctions' OR 'dysfunction, cognitive' OR 'dysfunctions, cognitive' OR 'cognitive impairments' $O R^{\prime}$ cognitive impairment'OR'impairment, cognitive'OR'impairments, cognitive'OR'mild cognitive impairment' OR 'cognitive impairment, mild' OR 'cognitive impairments, mild' OR 'impairment, mild cognitive' OR 'impairments, mild cognitive' OR'mild cognitive impairments' OR'mild neurocognitive disorder'OR'disorder, mild neurocognitive' OR'disorders,

EMBASE mild neurocognitive' OR 'mild neurocognitive disorders' OR 'neurocognitive disorder, mild' OR 'neurocognitive disorders, mild' OR 'cognitive decline' OR 'cognitive declines' OR'decline, cognitive' OR 'declines, cognitive' OR 'mental deterioration' OR 'deterioration, mental' OR'deteriorations, mental' OR'mental deteriorations') AND ('mass screening' OR'mass screenings' OR 'screening, mass' OR 'screenings, mass' OR screening*)) AND ('controlled clinical trial'/de OR'randomized controlled trial'/de OR'randomized controlled trial topic'/de) AND ([aged]/lim OR [very elderly]/lim)

("Disfunção cognitiva" OR "Comprometimento Cognitivo" OR "Comprometimento Cognitivo Leve" OR "Declínio Cognitivo" LILACS OR“Deficiências Cognitivas" OR “Deterioração Mental” OR“Distúrbio Neurocognitivo Leve"OR "Transtorno Neurocognitivo Leve") AND ("Programas de rastreamento" OR "Exame Coletivo" OR "Identificação Sistemática" OR rastreamento OR screening OR "Triagem de Massa") AND ( db:("LILACS") AND limit:("aged"))

(((Cognitive Dysfunction*) OR (Dysfunction, Cognitive) OR (Dysfunctions, Cognitive) OR (Cognitive Impairments) OR (Cognitive Impairment) OR (Impairment, Cognitive) OR (Impairments, Cognitive) OR (Mild Cognitive Impairment) OR (Cognitive Impairment, Mild) OR (Cognitive Impairments, Mild) OR (Impairment, Mild Cognitive) OR (Impairments, Mild Cochrane Cognitive) OR (Mild Cognitive Impairments) OR (Mild Neurocognitive Disorder) OR (Disorder, Mild Neurocognitive) OR Library (Disorders, Mild Neurocognitive) OR (Mild Neurocognitive Disorders) OR (Neurocognitive Disorder, Mild) OR (Neurocognitive Disorders, Mild) OR (Cognitive Decline) OR (Cognitive Declines) OR (Decline, Cognitive) OR (Declines, Cognitive) OR (Mental Deterioration) OR (Deterioration, Mental) OR (Deteriorations, Mental) OR (Mental Deteriorations)) AND ((Mass Screening*) OR (Screening, Mass) OR (Screenings, Mass) OR (Screening*)) and ((AGED) OR (AGED, 80 AND OVER)))

Any disagreements in the selection process were resolved through reaching a consensus or by consulting a third author (JEM). To assess the methodological quality of the studies included, the Downs \& Black checklist was used, ${ }^{17}$ with adaptation for RCTs and observational studies. For the RCTs, all questions from this tool were used, with a maximum score of 28 points. For the observational studies, the 17 questions from the original list were used, totaling a maximum of 18 points.

\section{RESULTS}

\section{Selection of articles}

We found 983 articles in the first stage of article selection, but 244 articles were excluded due to duplication in the research databases. Thus, 739 articles were retained for assessment of eligibility. In the next phase, articles that did not have the research topic in the title or abstract were excluded. Thus, a further 690 articles were excluded and 49 were selected for assessment of eligibility. Of these, only 16 articles met the objectives of this scoping review (Figure 1).
Tables 2 and 3 provide details on the studies included, so that readers can make their own judgments about the research in these studies.

\section{Results from blinded randomized clinical trials (RCTs)}

The RCTs (Table 2) were conducted on a total population of 10,445 people, with a weighted average age of 77.49 years. The educational level was only recorded in the study by Fowler et al. ${ }^{18}$

In these studies, four instruments were used, which were all cognitive assessment tests: memory impairment screening (MIS), Mini-Cog, DemTect and clock drawing test ${ }^{19}$ (CDT).

The RCT by Fowler et al. ${ }^{18}$ did not detect any differences in healthcare, quality of life or harm from symptoms of depression and anxiety among individuals who were screened as positive for dementia, through application of MIS or Mini-Cog. ${ }^{18}$

Reiner et al. ${ }^{20}$ compared positive results from cognitive screening using DemTect with the results obtained through the CDT. ${ }^{19}$ They suggested that the $\mathrm{CDT}^{19}$ was not a suitable instrument for detection of probable dementia within primary care. ${ }^{20}$ 


\section{Results from observational studies (OS)}

The sample size in the 14 observational studies (OS) ranged from 50 to 15,051 . It was in the range of up to 100 in one article; 101 to 1,000 in seven articles; 1,001 to 10,000 in five articles and more than 10,000 in one article. The total population of the OSs was 35,010 individuals (Table 3).

The participants' cognitive status was classified as follows: cognitively normal $(\mathrm{CN})$; cognitive impairment with no dementia (CIND); mild cognitive impairment (MCI); and dementia in its respective clinical stages of evolution.

Among the observational studies, 19 instruments (14 cognitive assessment tests and five functional assessment scales) were used to screen the cognition of individuals aged 60 years or over (Tables 4 and 5).

\section{DISCUSSION}

The criteria used for analysis in this scoping review, on the instruments that might be best suited for use in the Brazilian population, were the following: quick application, validation for use in primary care locations or in the community; adequate psychometric properties; ease of application by members of the healthcare team; the least possible influence from the subject's educational and cultural level; and whether elderly people's interest in the evaluation was aroused. The sensitivity and specificity of screening instruments for cognitive impairment among the elderly were also considered.

Use of indiscriminate screening, i.e. for the entire elderly population, irrespective of any cognitive complaints, has been controversial. This is not only because of the need for adaptations to instruments, for them to be applied (given the lack of standardization), ${ }^{21}$ but also because positive results could lead to harm such as anxiety and depression among individuals without any proven dementia. Nonetheless, in the RCT conducted by Fowler et al., ${ }^{18}$ no harm due to symptoms of depression and anxiety was found after positive screening for dementia. ${ }^{18}$

DemTect $^{22}$, the instrument used by Reiner et al. ${ }^{20}$ is composed of the following tests that are already used in the Brazilian population: immediate memory of a word list, late evocation of the same list, a numerical coding test, a span digit test and a semantic verbal fluency test. ${ }^{23}$ Those researchers did not consider that screening by means of the $\mathrm{CDT}^{19}$ to detect probable dementia was an adequate method. ${ }^{24}$ Although the $\mathrm{CDT}^{19}$ is easy to apply, it is vulnerable to different interpretations of the final result, given that different ways to analyze the clock that was drawn have been found. It cannot be used among people with visual or motor difficulties that prevent them from properly handling paper and pen, to make the drawing. There is no consensus on whether the $\mathrm{CDT}^{19}$ can distinguish MCI from dementia, even though this test can assess memory, motor and executive function and verbal comprehension, and

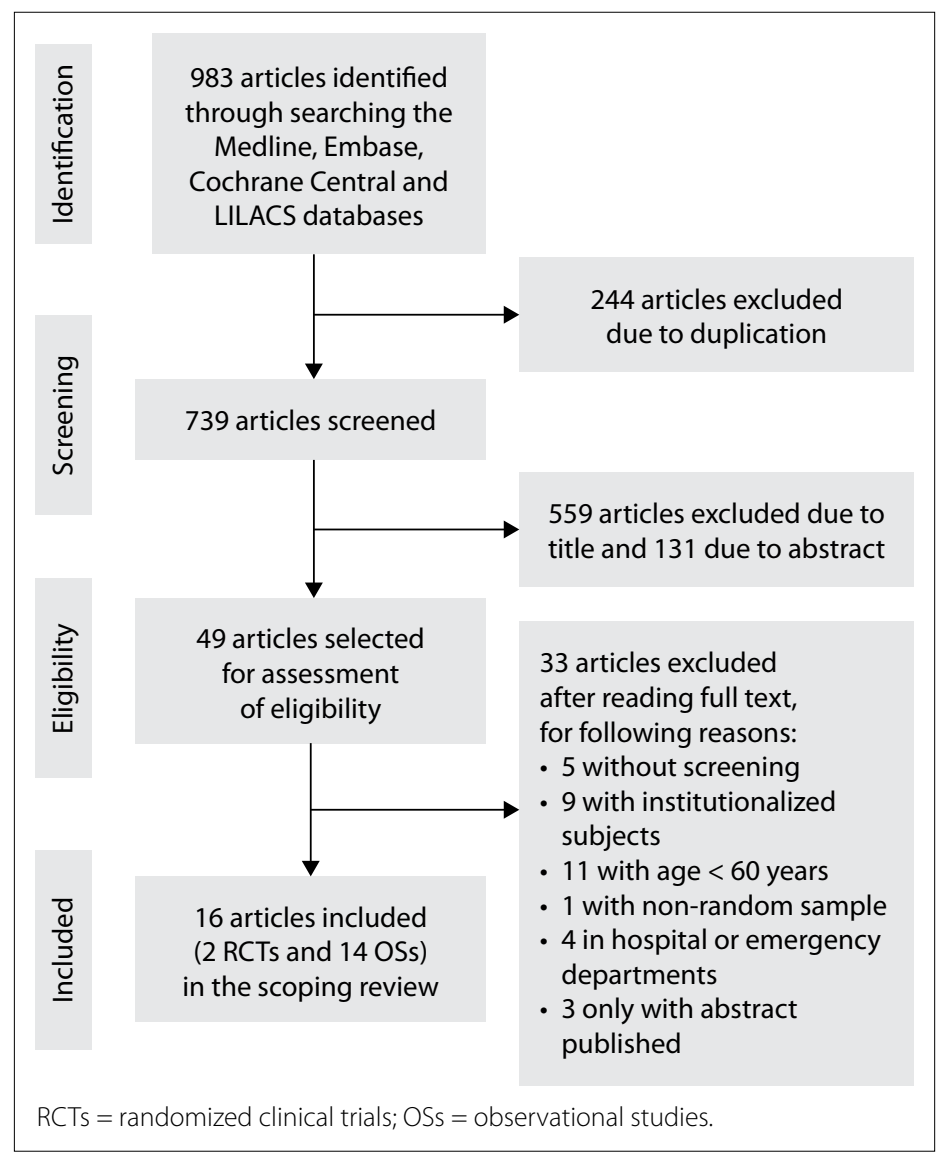

Figure 1. Flowchart for identifying and selecting articles for this scoping review.

has been shown to differentiate dementia from normal cognition in review studies. ${ }^{25}$

The Mini-Cog ${ }^{26}$ includes the CDT, ${ }^{19}$ with its characteristics as described above, along with immediate and late evocation of three repetitions of words. In the study by Fowler et al., ${ }^{18}$ MiniCog was applied together with MIS. Those authors concluded that Mini-Cog was suitable for routine screening within primary care. However, this test has not been recognized as a good tool for cognitive screening among elderly people in the Brazilian population with less than five years of formal education. ${ }^{27}$

The memory impairment screening (MIS) ${ }^{28}$ test was recommended for use in the Medicare Annual Wellness Visit as a preliminary test in conjunction with other screening tools. It can be effectively applied within four minutes to identify cognitive impairment, ${ }^{29}$ and does not require the ability to write. However, an ability to read is required, which thus means that the results from this test are influenced by the subject's educational level. ${ }^{30}$

The Montreal Cognitive Assessment (MoCA) ${ }^{31}$ is a test that was designed to screen for MCI and to differentiate it from dementia. ${ }^{31}$ Although it covers all cognitive domains, it is significantly influenced by age and level of formal education. $\mathrm{MoCA}^{31}$ may be 
Table 2. Randomized Clinical Trials

\begin{tabular}{|c|c|c|c|c|c|c|}
\hline $\begin{array}{l}\text { Authors, year } \\
\text { and country }\end{array}$ & Study design & $\begin{array}{l}\text { Population } \\
\text { and setting }\end{array}$ & Intervention & Comparison & Main findings & $\begin{array}{c}\text { Down } \\
\text { \& Black } \\
\text { (maximum } \\
\text { score: } 28 \text { ) }\end{array}$ \\
\hline $\begin{array}{l}\text { Reiner } \\
\text { et al., }{ }^{20} 2018 \text {; } \\
\text { Germany }\end{array}$ & $\begin{array}{c}\text { Cluster- } \\
\text { randomized } \\
\text { controlled } \\
\text { intervention } \\
\text { trial; } \\
\text { ClinicalTrials. } \\
\text { gov identifier } \\
\text { NCT01401582 }\end{array}$ & $\begin{array}{l}6,440 \text { primary } \\
\text { care patients } \\
\text { systematically } \\
\text { screened for } \\
\text { dementia }\end{array}$ & $\begin{array}{c}\text { DemTect } \\
\text { and clock } \\
\text { drawing test } \\
\text { (CDT) }\end{array}$ & $\begin{array}{c}1,601 \text { subjects ( } 41.6 \% \\
\text { men and } 58.4 \% \text { women); } \\
\text { mean age } 76 \pm 5.3 \text { years } \\
\text { (range } 70 \text { to } 95 \text { years); after } \\
\text { DemTect screening, they } \\
\text { were assessed using CDT }\end{array}$ & $\begin{array}{l}\text { DemTect is a dementia screening } \\
\text { instrument used in Germany with } \\
\text { sensitivity of } 100 \% \text { and specificity of } 92 \% \text {; } \\
\text { 17.3\% ( } \mathrm{n}=1,117 \text { ) of the total sample ( } \mathrm{n} \\
=6,440 \text { ) were categorized as presenting } \\
\text { probable dementia (DemTect score < } \\
\text { 9). The sensitivity and specificity of CDT } \\
\text { were } 84.4 \% \text { and } 45.6 \% \text { respectively. } \\
\text { CDT cannot be regarded as a suitable } \\
\text { instrument for detection of probable } \\
\text { dementia in primary care. Multi domain } \\
\text { tests like DemTect should be considered } \\
\text { more appropriate for identifying probable } \\
\text { dementia in primary care }\end{array}$ & $\begin{array}{c}25 \\
\text { points/28 }\end{array}$ \\
\hline $\begin{array}{l}\text { Fowler et al., }{ }^{18} \\
\text { 2019; United } \\
\text { States }\end{array}$ & $\begin{array}{c}\text { Single- } \\
\text { blinded, } \\
\text { two-arm, } \\
\text { randomized } \\
\text { controlled } \\
\text { trial; } \\
\text { ClinicalTrials. } \\
\text { gov identifier } \\
\text { NCT01699503 }\end{array}$ & $\begin{array}{c}4,005 \text { primary } \\
\text { care patients; } \\
\text { mean age } \\
\text { of the } \\
\text { overall study } \\
\text { population } \\
\text { was } 74.1 \text { ( } \pm \\
6.9) ; 2,256 \\
(66 \%) \text { were } \\
\text { female }\end{array}$ & $\begin{array}{l}\text { Memory } \\
\text { impairment } \\
\text { screening } \\
\text { (MIS) and } \\
\text { Mini-Cog }\end{array}$ & $\begin{array}{l}\text { 2,008 patients randomized } \\
\text { to screening for Alzheimer } \\
\text { disease and related } \\
\text { dementias (ADRD) and } \\
\text { 1,997 patients randomized } \\
\text { to no ADRD screening. } \\
\text { Primary measurements } \\
\text { were health-related quality } \\
\text { of life at } 12 \text { months and } \\
\text { symptoms of depression } \\
\text { and anxiety at } 1 \text { month }\end{array}$ & $\begin{array}{l}\text { A total of } 134 \text { participants (7.7\%) in } \\
\text { the screening arm screened positive in } \\
\text { either MIS or Mini-Cog. Symptoms of } \\
\text { depression and anxiety were not harmed } \\
\text { through screening and their scores were } \\
\text { similar between screened and non- } \\
\text { screened ADRD groups. No differences in } \\
\text { healthcare utilization, advance planning } \\
\text { of care or ADRD recognition by physicians } \\
\text { were detected at } 12 \text { months }\end{array}$ & $\begin{array}{c}26 \\
\text { points/28 }\end{array}$ \\
\hline
\end{tabular}

not an suitable instrument for identifying CIND among individuals with lower levels of education, according to a study by César et al. ${ }^{32}$ However, Cecato et al. ${ }^{33}$ found that MoCA was the test with the highest predictive value for differentiating Alzheimer's dementia (AD) from MCI and also for differentiating cases of MCI from normal individuals. Furthermore, MoCA has been shown to have significant correlations with the age variable in the mini-mental state examination (MMSE), ${ }^{34}$ Cambridge Cognitive Examination (CAMCOG), ${ }^{35} \mathrm{CDT},{ }^{19}$ verbal fluency test (VFT) ${ }^{36}$ and Pfeffer Functional Activities Questionnaire (PFAQ), ${ }^{37}$ which are instruments that have already been validated and are widely used in the Brazilian population. ${ }^{33}$ Although MoCA ${ }^{31}$ has the disadvantage of taking longer to apply than $\mathrm{MMSE}^{34}$ and presents limitations with regard to the capacity for illiterate individuals to perform the proposed tasks, it is a tool that provides a superior overall assessment in the early stages of cognitive decline. ${ }^{38}$

Burkart et al. ${ }^{39}$ compared the selective reminding procedure ${ }^{40}$ (SRP) with $\mathrm{MMSE}^{34}$ and concluded that the SRP was not recommendable for cognitive screening for dementia. ${ }^{40}$ The Fuld Object Memory Evaluation (FOME) ${ }^{41}$ assesses memory and learning through the SRP and can be applied to elderly people with a low level of formal education. It uses late evocation after distraction and is applied through a semantic VFT. ${ }^{36}$ In Brazil, the only studies found involved a professional trained in psychology as the evaluator of this test. ${ }^{42,43}$

The $\mathrm{MMSE}^{34}$ was the instrument most cited and used in this scoping review, thus corroborating other findings reported in the literature. ${ }^{21,44}$ It has been validated for application both in the community and in primary care in many countries, with the aim of increasing the recognition of cognitive impairment. It has been accepted both by patients and by interviewers, even without assessment of executive function. ${ }^{29}$

Despite being widely used in Brazil, $\mathrm{MMSE}^{34}$ needs adjustments to its cutoff scores, which are variable, because it can be influenced by age and level of formal education. ${ }^{45}$ It is a screening tool that can be applied rapidly, and it addresses the main cognitive domains with high specificity and sensitivity for dementia. A wide variety of healthcare professionals have the capacity to use it. ${ }^{46}$

The criteria used in the MMSE ${ }^{34}$ make it highly capable of screening for moderate and severe cognitive impairment. However, its ability to signal milder or earlier degrees of cognitive decline is significantly lower. It is not suitable for screening for the initial phases of dementia and can lead to higher rates of false negative results, since it does not evaluate executive function. ${ }^{47}$ 


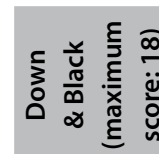

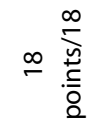

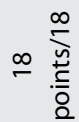

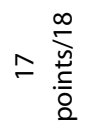

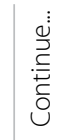

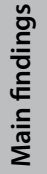

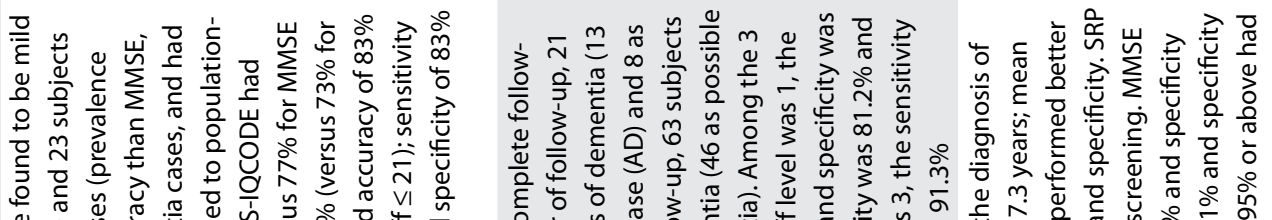

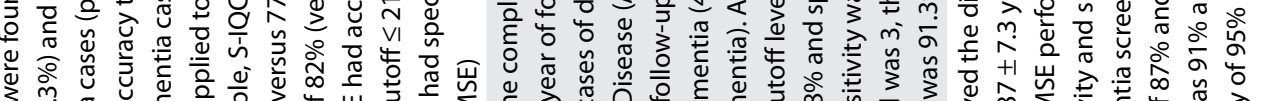

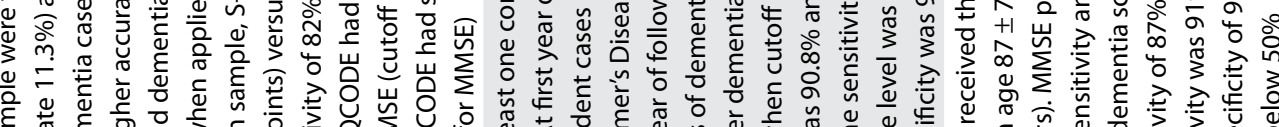

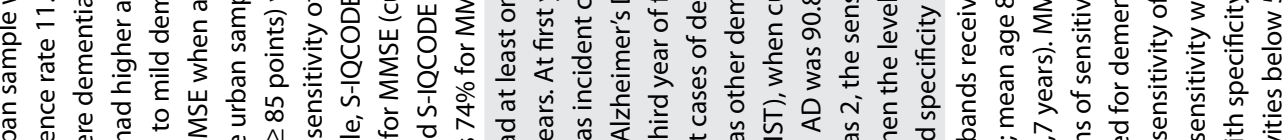

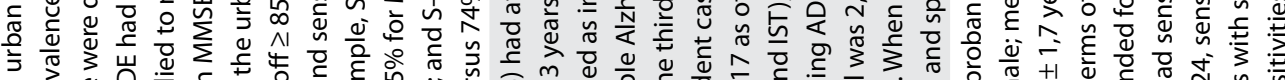

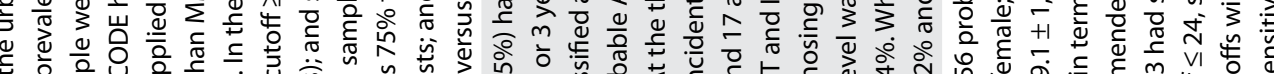

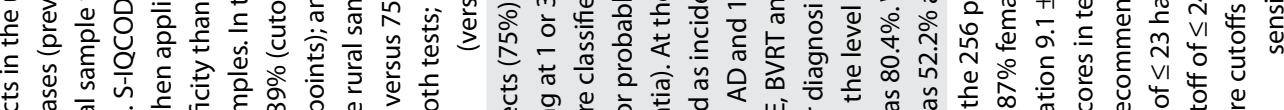

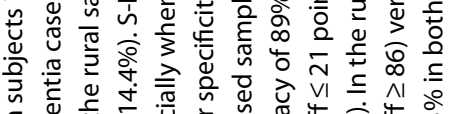

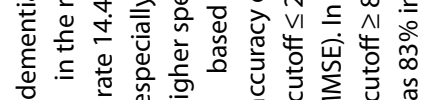

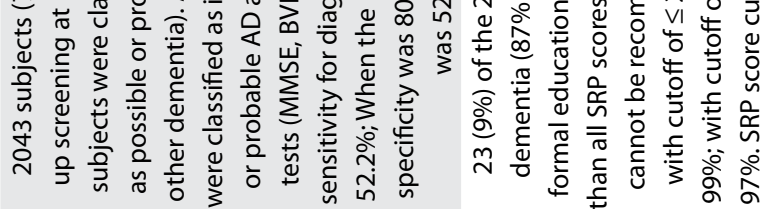
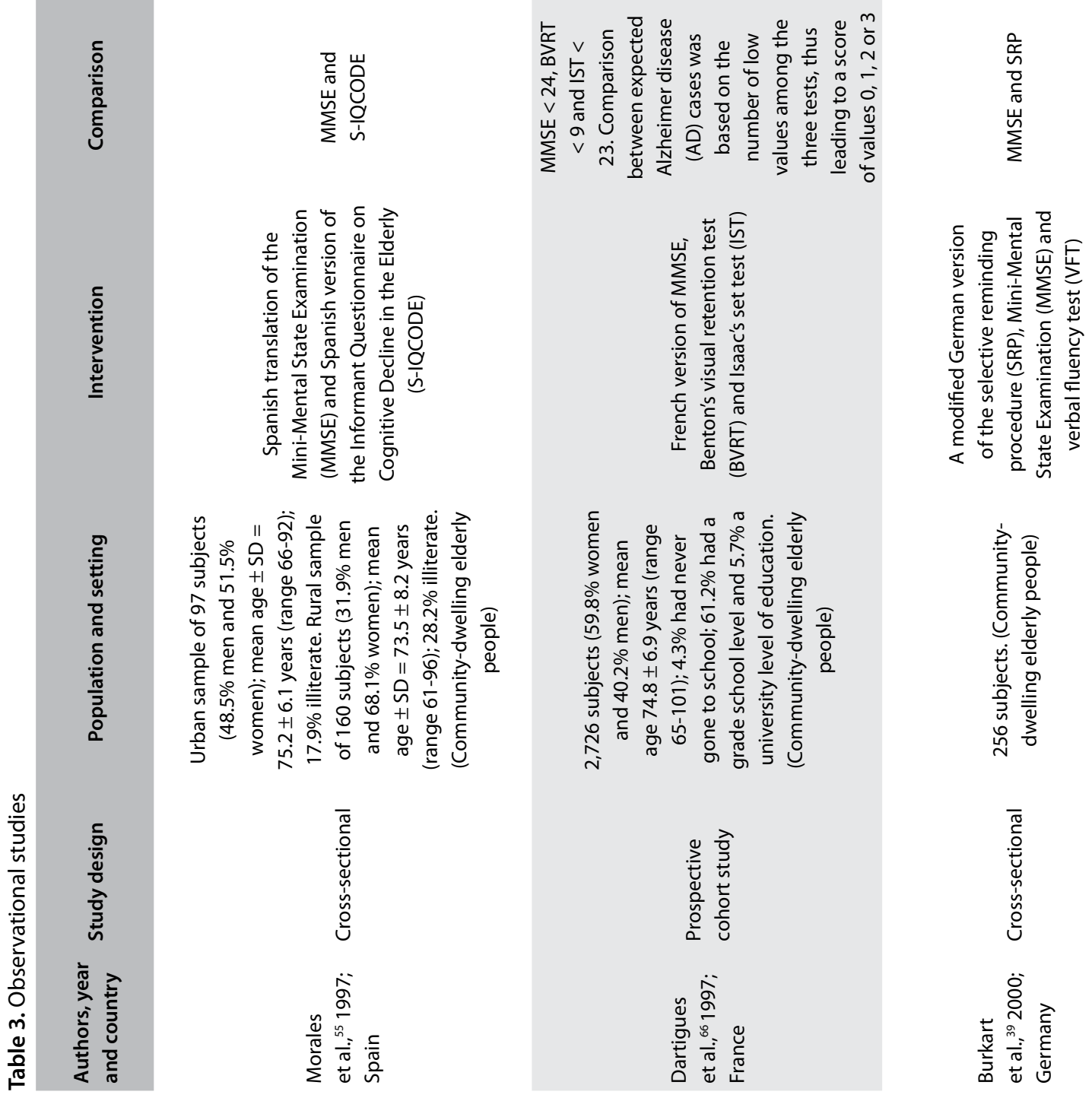


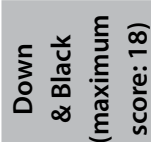

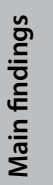
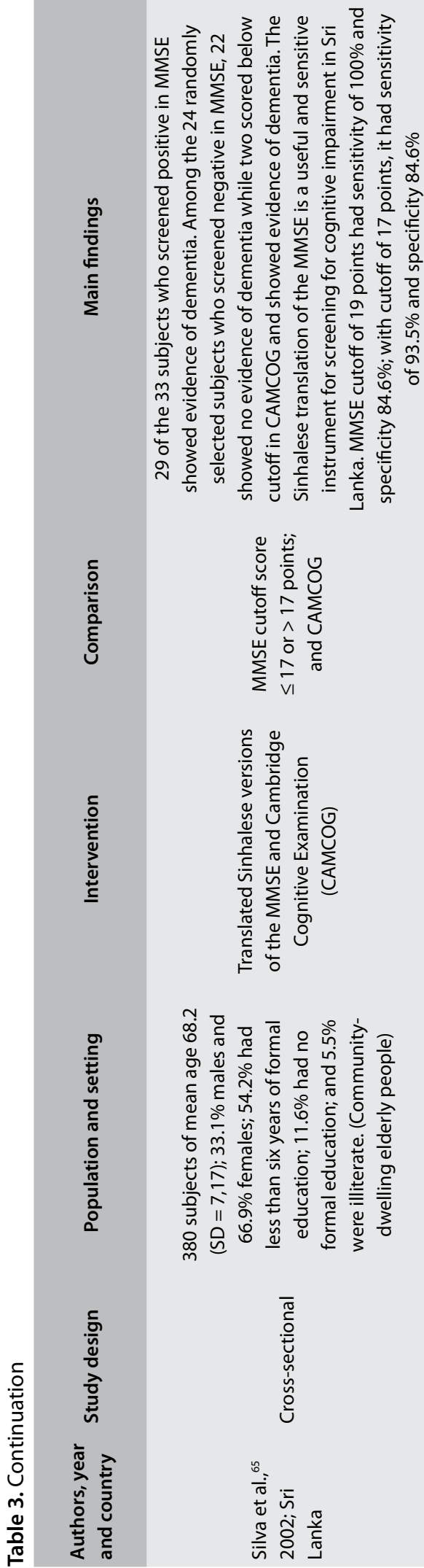

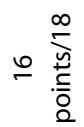

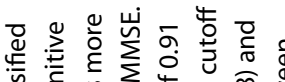

药

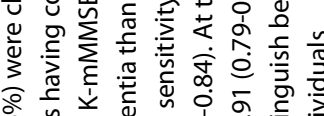

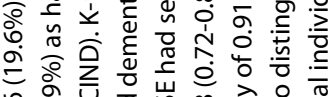

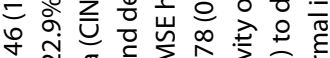

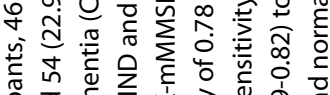

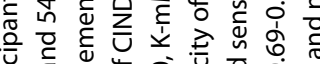

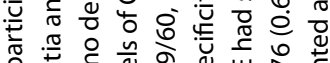

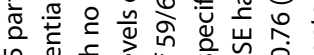

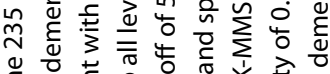

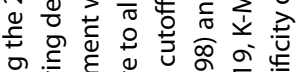

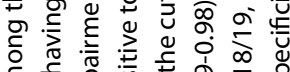

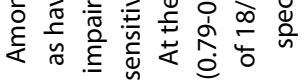

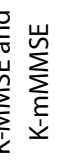
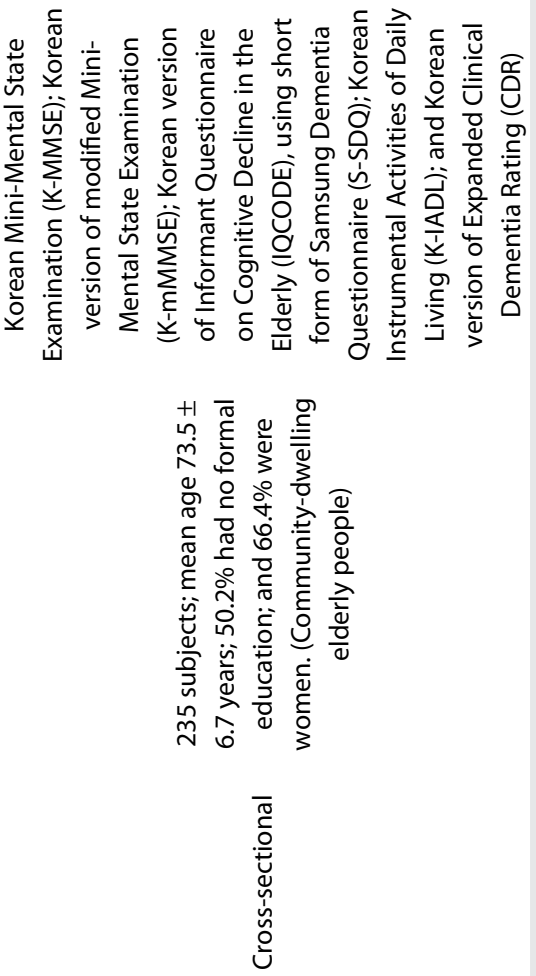

竞离

吾

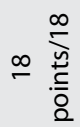

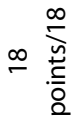

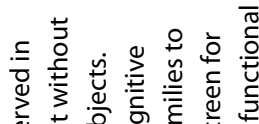

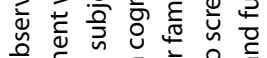

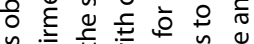

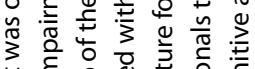

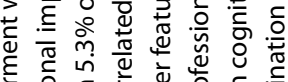

है

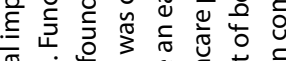

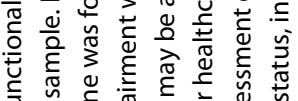

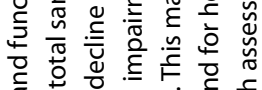

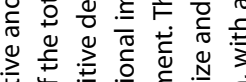

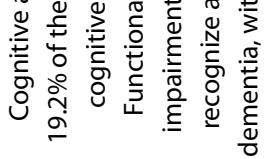

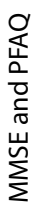

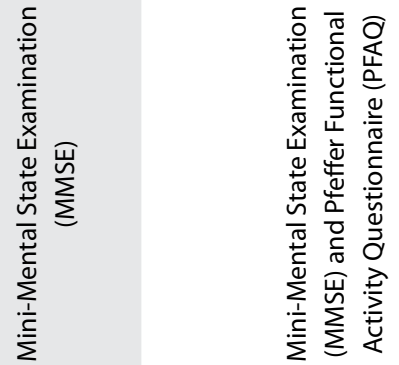

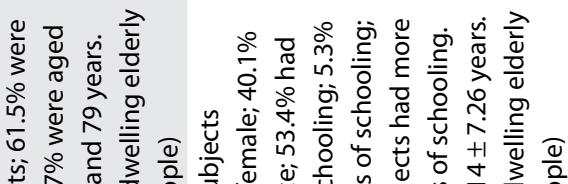

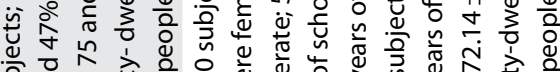

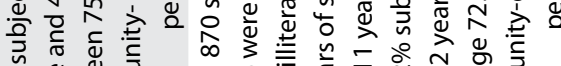

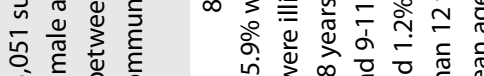

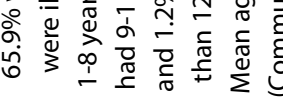

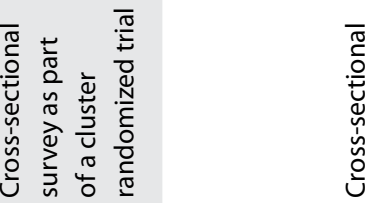

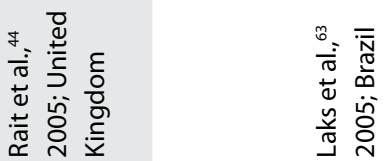




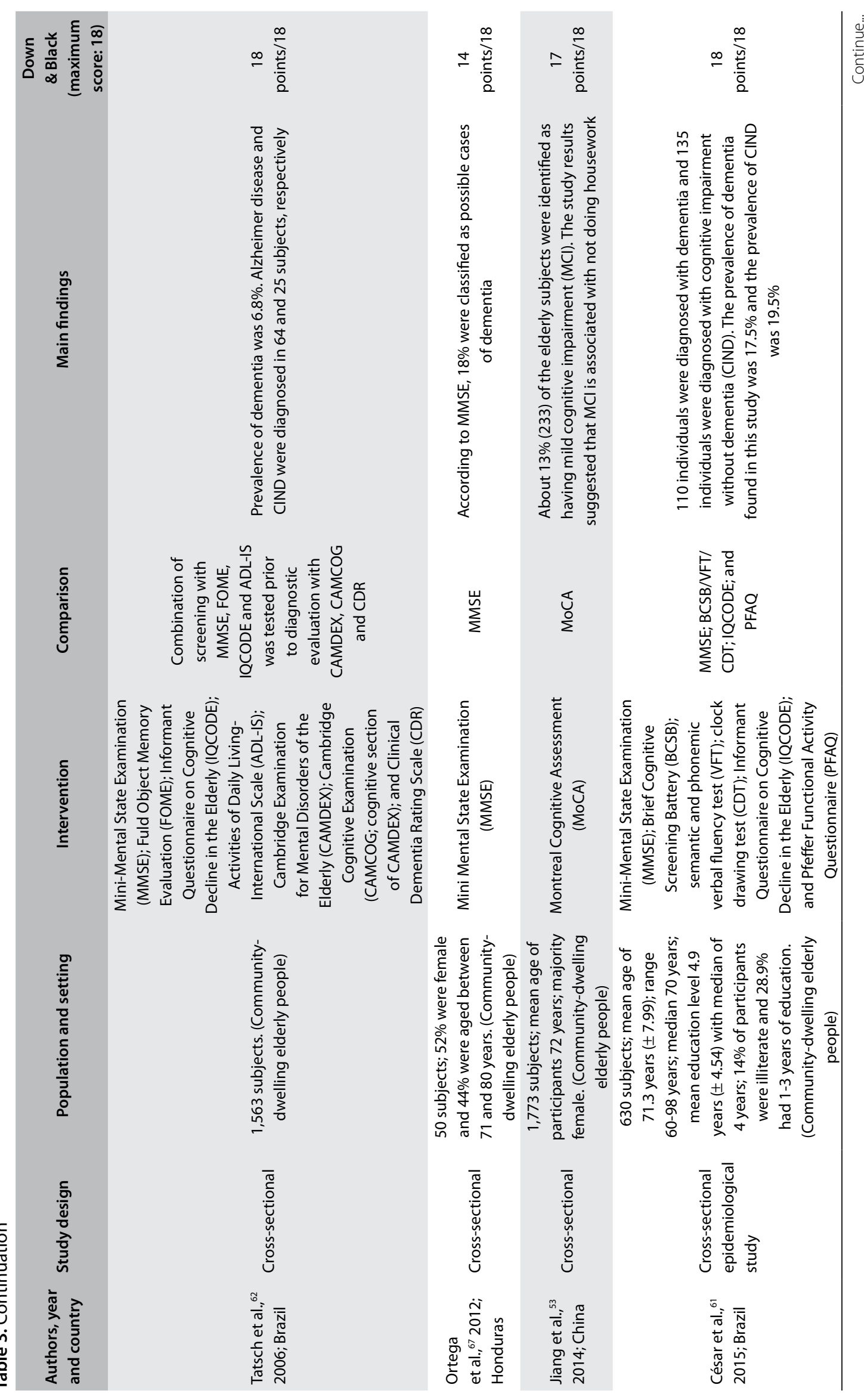




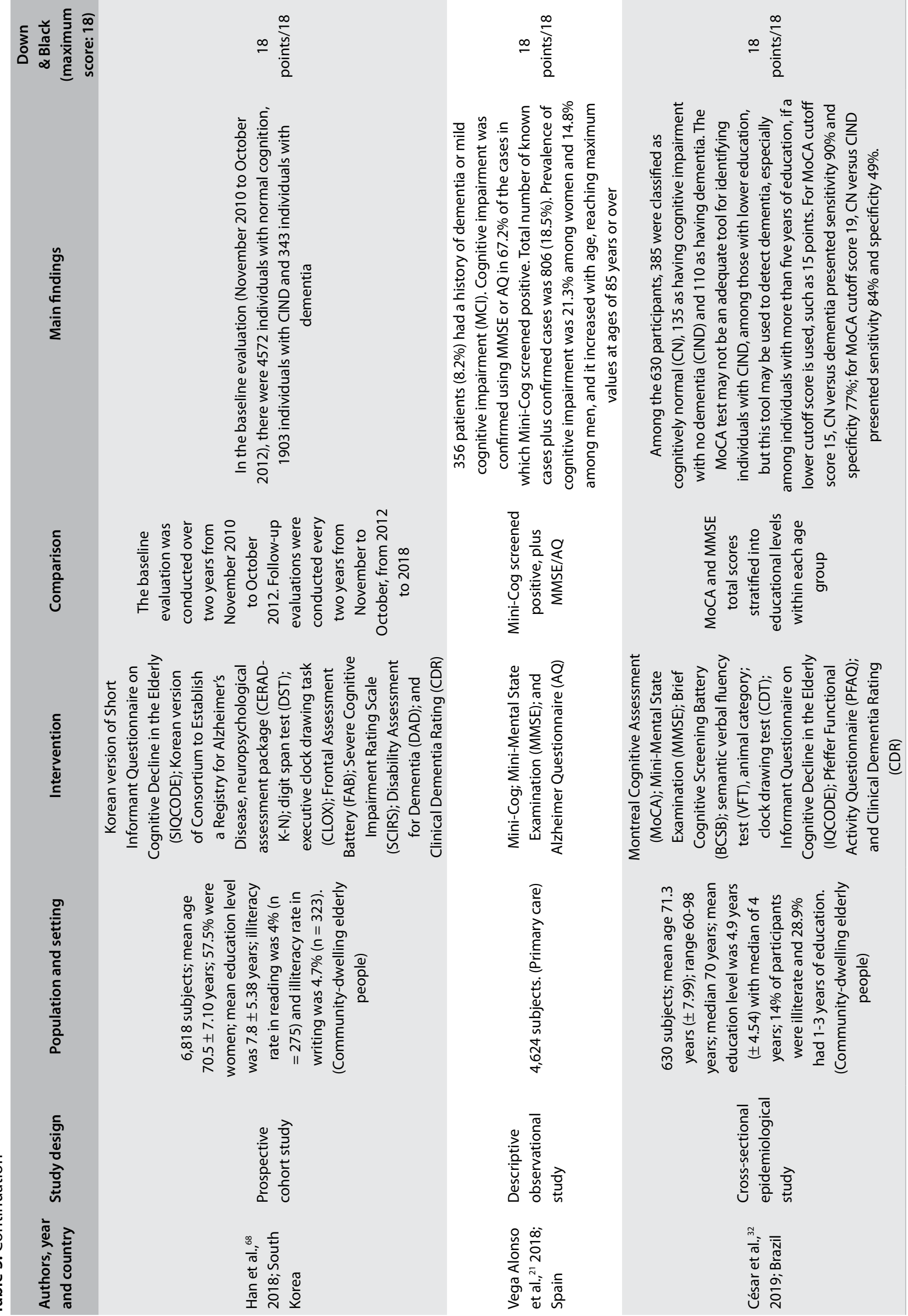


Table 4. Cognitive assessment test

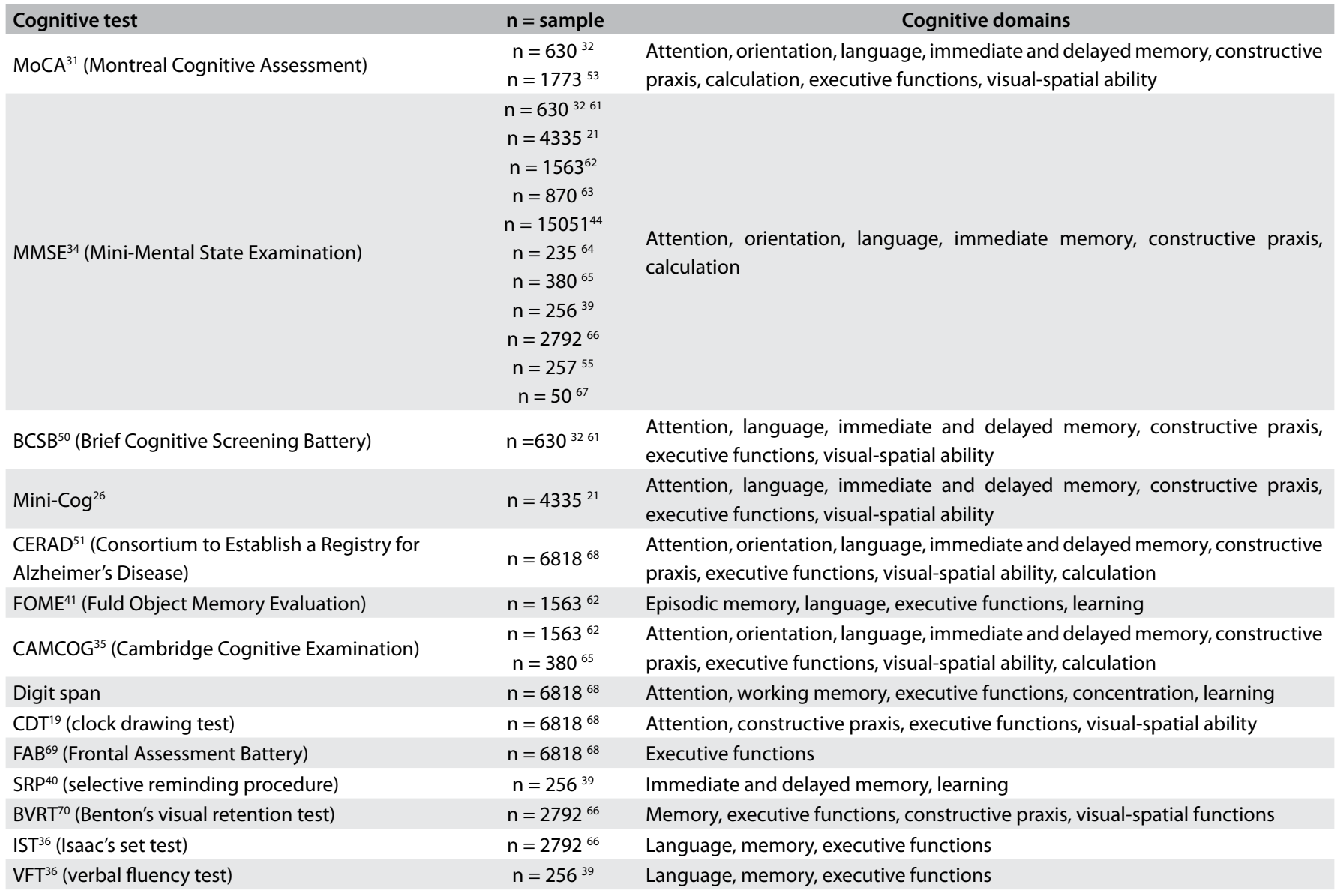

Source: Observational studies.

Table 5. Functional evaluation scale

\begin{tabular}{|c|c|}
\hline Functional scale & $\mathrm{n}=$ sample \\
\hline $\begin{array}{l}\text { IQCODE }^{54} \text { (Informant Questionnaire on Cognitive } \\
\text { Decline in the Elderly) }\end{array}$ & $\begin{array}{c}n=630^{32} \\
n=1563^{60} \\
n=257^{53}\end{array}$ \\
\hline PFAQ $^{37}$ (Pfeffer Functional Activity Questionnaire) & $\begin{array}{l}n=630^{32} 5 \\
n=870^{61}\end{array}$ \\
\hline $\mathrm{CDR}^{56}$ (Clinical Dementia Rating) & $\begin{array}{l}\mathrm{n}=630^{32} \\
\mathrm{n}=1563^{60}\end{array}$ \\
\hline $\mathrm{AQ}^{71}$ (Alzheimer's Questionnaire) & $\mathrm{n}=4335^{21}$ \\
\hline SCIRS $^{72}$ (Severe Cognitive Impairment Rating Scale) & $\mathrm{n}=6818^{66}$ \\
\hline
\end{tabular}

\section{Cognitive and functional domains and activities of daily living}

Memory, orientation, judgment and problem solving, community affairs, home and hobbies, personal care

Memory, orientation, judgment and problem solving, community affairs, home and hobbies, personal care

Memory, orientation, judgment and problem solving, community affairs, home and hobbies, personal care

Memory, orientation, judgment and problem solving, community affairs, home and hobbies, personal care

Memory, orientation, motor function, visuospatial function, language

Source: Observational studies.

Changes in executive function may be present early in cases of dementia syndrome, and even as the only manifestations. It needs to be emphasized that the $\mathrm{MMSE}^{34}$ should not be used in isolation to assess cognitive performance. ${ }^{48,49}$

Use of the semantic VFT ${ }^{36}$ was also seen among the studies reviewed. This enables evaluation of language, memory and executive function, through asking individuals to verbally list categories of colors, animals, fruits or cities. Although it was considered separately only in one study, it was used in other articles in this scoping review, within the FOME ${ }^{41}$ and $\mathrm{CAMCOG}^{34}$ tests, the Brief Cognitive Screening Battery ${ }^{50}$ (BCSB), the Consortium to Establish a Registry for Alzheimer's Disease (CERAD) $)^{51}$ battery and the $\mathrm{MoCA}^{31}$ test (phonology version).

VFT $^{36}$ is a simple test that can easily be applied. It presents screening results that classify cognition with precision comparable to that of MMSE, ${ }^{34}$ given that it is very effective in evaluating 
executive function and language ability, mainly due to its semantic approach, which seems to require a high level of thought process. The semantic and phonological versions of $\mathrm{VFT}^{36}$ can be considered to be indicators of executive functions since this test requires the ability to self-regulate working memory through the ability to search for and retrieve information that is stored in long-term memory. $\mathrm{VFT}^{36}$ is considered to be quite accurate for dementia screening and relatively sensitive for assessing earlier stages of cognitive impairment. The levels of resistance or refusal to participate are low because listing words for one minute is not particularly intimidating. This test is free of charge and easy to administer. It does not require any materials other than a device to keep track of the time and a means for recording the number of words produced. VFT ${ }^{36}$ appears to be able to distinguish between individuals with or without normal cognition. Performance in this test may be influenced by the subject's level of education and age, which therefore needs to be taken into account. ${ }^{8,52}$

Jiang et al. ${ }^{53}$ suggested that changes to instrumental activities of daily living (IADLs) for domestic work may occur in individuals with MCI and, therefore, use of functional scales is also recommendable. Furthermore, according to Rait et al., ${ }^{44}$ individuals with CIND presented higher levels of functional deficit than people with intact cognition.

The Informant Questionnaire on Cognitive Decline in the Elderly (IQCODE) ${ }^{54}$ is a questionnaire (via an interview) that is applied to an individual who accompanies a patient. This companion is asked to quantify the patient's current performance in different activities of daily living (ADLs), in comparison with the same situations 10 years ago. Morales et al. ${ }^{55}$ showed that the $\mathrm{IQCODE}^{54}$ scale presented greater precision of results than the MMSE, ${ }^{34}$ in cases of MCI.

$\mathrm{PFAQ}^{37}$ was the functional assessment questionnaire that was most used among the studies reviewed here. It was also aimed at accompanying informants, who were asked to answer 10 simple questions about the performance of elderly people regarding their ADLs. These results can provide direct sensitive information, within the primary care setting, regarding the companion's suspicion that the patient may present dementia. Use of $\mathrm{PFAQ}^{37}$ combined with VFT $^{36}$ showed sensitivity of $88.3 \%$ and specificity of $76.5 \%$ in a study by Jacinto et al., ${ }^{5}$ thus suggesting that these tests are useful for screening for cognitive impairment among elderly people.

The Clinical Dementia Rating (CDR ${ }^{56}$ scale assesses behavior and cognition among elderly people and ascertains the degree of dementia when present. It is capable of identifying individuals for whom the criteria for dementia have not yet been established, but who present cognitive impairment. This instrument is divided into six cognitive and behavioral functions, in order to assess the influence that cognitive impairment can have on the functional capacity to perform ADLs. ${ }^{57}$
The articles selected for the present review showed certain limitations. These included the rate of losses and the short follow-up period for the patients in the RCTs. ${ }^{18,20}$ There was also selection bias in the subsample categories, when tests at different times of assessment were compared. Furthermore, there was no reassessment of participants with a negative result from screening for cognitive impairment. ${ }^{53}$ Evaluation of a sample of patients from primary care and not from the community in general was criticized in some studies, ${ }^{18,20,21}$ but this met the inclusion criteria of this scoping review. In addition, given that cognitive impairment can begin many years before dementia syndromes are diagnosed, ${ }^{58}$ further studies on cognitive screening among younger individuals are needed. For example, individuals aged 40 to 60 , who may or may not have subjective cognitive complaints, could be assessed. The instruments that were relevant in this review, such as MMSE, ${ }^{34} \mathrm{VFT}^{36}$ and PFAQ, ${ }^{37}$ could be used in such studies.

\section{CONCLUSIONS}

The $\mathrm{MMSE}^{34}$ was the test most frequently found, and its use and limitations were discussed here. The findings from this scoping review suggest that additional studies on the use of the PFAQ,${ }^{37}$ in combination with the VFT, ${ }^{36}$ for screening for cognitive impairment among elderly people in the Brazilian population, should be conducted. The positive characteristics of these tools include the reliability of their results; the lower influence of the level of formal education, compared with other instruments; and their ease of application. These additional studies should comprise randomized clinical trials and observational studies to assess the application of $\mathrm{PFAQ}^{37}$ and $\mathrm{VFT}^{36}$ within primary care, given the diversity of educational and cultural levels in Brazil.

It also necessary to create new cognitive screening instruments for future studies, with the characteristics common to the MMSE, ${ }^{34}$ $\mathrm{VFT}^{36}$ and PFAQ, ${ }^{37}$ such as ease of application, in order to obtain standardized results. General practitioners within primary care services can then apply such instruments to elderly people, in order to be able to refer them for wide-ranging and timely evaluation in specialized services, when necessary.

In the context of aging of the population, it is important that professionals should screen for cognitive impairment, ${ }^{59,60}$ as a routine procedure within primary healthcare. Through this, preventive interventions can be provided in order to avoid or minimize the negative effects of dementia on elderly people's health.

\section{REFERENCES}

1. Parant A. Les perspectives démographiques mondiales [World population prospects]. Futuribles. 1990;(141):49-78. PMID: 12283219.

2. Instituto Brasileiro de Geografia e Estatística. Projeção da população do Brasil e das Unidades da Federação. População do Brasil [Internet]. 
IBGE; 2020. Available from: https://www.ibge.gov.br/apps/populacao/ projecao/. Accessed in 2021 (Mar 25).

3. Brasil. Ministério da Saúde. Orientações técnicas para a implementação de linha de cuidado para atenção integral à saúde da pessoa idosa. Brasília (DF): Ministério da Saúde; 2018.

4. Tangalos EG, Petersen RC. Mild Cognitive Impairment in Geriatrics. Clin Geriatr Med. 2018;34(4):563-89. PMID: 30336988; https://doi. org/10.1016/j.cger.2018.06.005.

5. Jacinto AF, Brucki SMD, Porto CS, Martins MA, Nitrini R. Screening of cognitive impairment by general internists using two simple instruments. Dement Neuropsychol. 2012;6(1):42-7. PMID: 29213771; https://doi.org/10.1590/S1980-57642012DN06010007.

6. Martins NIM, Caldas PR, Cabral ED, Lins CCDSA, Coriolano MDGWS. Cognitive assessment instruments used in elderly Brazilians in the last five years. Cien Saude Colet. 2019;24(7):2513-30. PMID: 31340270; https://doi.org/10.1590/1413-81232018247.20862017.

7. Bustamante $\mathrm{SE}$, Bottino CM, Lopes MA, et al. Instrumentos combinados na avaliação de demência em idosos: resultados preliminares [Combined instruments on the evaluation of dementia in the elderly: preliminary results]. Arq Neuropsiquiatr. 2003;61(3A):601-6. PMID: 14513165; https:// doi.org/10.1590/s0004-282×2003000400014.

8. Jacinto AF, Brucki S, Porto CS, Martins Mde A, Nitrini R. Detection of cognitive impairment in the elderly by general internists in Brazil. Clinics (Sao Paulo). 2011;66(8):1379-84. PMID: 21915487; https://doi. org/10.1590/S1807-59322011000800012.

9. Yassuda MS, da Silva HS, Lima-Silva TB, et al. Normative data for the Brief Cognitive Screening Battery stratified by age and education. Dement Neuropsychol. 2017;11(1):48-53. PMID: 29213493; https://doi. org/10.1590/1980-57642016dn11-010008.

10. Kivipelto M, Solomon A, Ahtiluoto S, et al. The Finnish Geriatric Intervention Study to Prevent Cognitive Impairment and Disability (FINGER): study design and progress. Alzheimers Dement. 2013;9(6):657-65. PMID: 23332672; https://doi.org/10.1016/j.jalz.2012.09.012.

11. Fage BA, Chan CC, Gill SS, et al. Mini-Cog for the diagnosis of Alzheimer's disease dementia and other dementias within a community setting. Cochrane Database Syst Rev. 2015;(2):CD010860. PMID: 25922857; https://doi.org/10.1002/14651858.CD010860.pub2.

12. Prorok JC, Horgan S, Seitz DP. Health care experiences of people with dementia and their caregivers: a meta-ethnographic analysis of qualitative studies. CMAJ. 2013;185(14):E669-80. PMID: 24003093; https://doi.org/10.1503/cmaj.121795.

13. Pereira AMVB, Rosa ACDS. Linha guia da saúde do idoso/SAS-SESA. Curitiba: SESA; 2018. Available from: https://www.saude.pr.gov. br/sites/default/arquivos_restritos/files/documento/2020-04/ linhaguiasaudeidoso_2018_atualiz.pdf. Accessed in 2021 (Mar 25).

14. Jacinto AF, Brucki SM, Porto CS, et al. Suggested instruments for General Practitioners in countries with low schooling to screen for cognitive impairment in the elderly. Int Psychogeriatr. 2014;26(7):1121-5. PMID: 24655588; https://doi.org/10.1017/S1041610214000325.
15. Patnode CD, Perdue LA, Rossom RC, et al. Screening for Cognitive Impairment in Older Adults: Updated Evidence Report and Systematic Review for the US Preventive Services Task Force. JAMA. 2020;323(8):764-85. PMID: 32096857; https://doi.org/10.1001/ jama.2019.22258.

16. Mclnnes MDF, Moher $\mathrm{D}$, Thombs BD, et al. Preferred Reporting Items for a Systematic Review and Meta-analysis of Diagnostic Test Accuracy Studies: The PRISMA-DTA Statement. JAMA. 2018;319(4):388-96. PMID: 29362800; https://doi.org/10.1001/jama.2017.19163. Erratum in: JAMA. 2019;322(20):2026.

17. Downs SH, Black N. The feasibility of creating a checklist for the assessment of the methodological quality both of randomised and non-randomised studies of health care interventions. J Epidemiol Community Health. 1998;52(6):377-84. PMID: 9764259; https://doi. org/10.1136/jech.52.6.377.

18. Fowler NR, Perkins AJ, Gao S, Sachs GA, Boustani MA. Risks and Benefits of Screening for Dementia in Primary Care:The Indiana University Cognitive Health Outcomes Investigation of the Comparative Effectiveness of Dementia Screening (IU CHOICE) Trial. J Am Geriatr Soc. 2020;68(3):53543. PMID: 31792940; https://doi.org/10.1111/jgs.16247.

19. Huntzinger JA, Rosse RB, Schwartz BL, Ross LA, Deutsch SI. Clock drawing in the screening assessment of cognitive impairment in an ambulatory care setting: a preliminary report. Gen Hosp Psychiatry. 1992;14(2):142-4. PMID: 1592251; https://doi.org/10.1016/0163-8343(92)90040-h.

20. Reiner K, EichlerT, Hertel J, Hoffmann W, Thyrian JR. The Clock Drawing Test: A Reasonable Instrument to Assess Probable Dementia in Primary Care? Curr Alzheimer Res. 2018;15(1):38-43. PMID: 28891446; https:// doi.org/10.2174/1567205014666170908101822.

21. Vega Alonso T, Miralles Espí M, Mangas Reina JM, et al. Prevalence of cognitive impairment in Spain: The Gómez de Caso study in health sentinel networks. Neurologia. 2018;33(8):491-8. PMID: 279391 16; https://doi.org/10.1016/j.nrl.2016.10.002.

22. Kalbe E, Kessler J, Calabrese P, et al. DemTect: a new, sensitive cognitive screening test to support the diagnosis of mild cognitive impairment and early dementia. Int J Geriatr Psychiatry. 2004;19(2):136-43. PMID: 14758579; https://doi.org/10.1002/gps.1042.

23. Kessler J, Calabrese P, Kalbe E. DemTect-B: ein Äquivalenztest zum kognitiven Screening DemTect-A [DemTect-B: A parallel test version to the cognitive screening instrument DemTect-A]. Fortschr Neurol Psychiatr. 2010;78(9):532-5. PMID: 20563965; https://doi. org/10.1055/s-0029-1245452.

24. Teixeira Fabricio A, Aprahamian I, Sanches Yassuda M. Qualitative analysis of the Clock Drawing Test by educational level and cognitive profile. Arq Neuropsiquiatr. 2014;72(4):289-95. PMID: 24760093; https://doi. org/10.1590/0004-282×20140004.

25. Lourenço RA, Ribeiro-Filho ST, Moreira Ide F, Paradela EM, Miranda AS. The Clock Drawing Test: performance among elderly with low educational level. Braz J Psychiatry. 2008;30(4):309-15. PMID: 19142404; https://doi.org/10.1590/s1516-44462008000400002. 
26. Borson S, Scanlan JM, Chen P, Ganguli M. The Mini-Cog as a screen for dementia: validation in a population-based sample. J Am Geriatr Soc. 2003;51(10):1451-4. PMID: 14511167; https://doi.org/10.1046/j.15325415.2003.51465.X...

27. Wilber ST, Lofgren SD, Mager TG, Blanda M, Gerson LW. An evaluation of two screening tools for cognitive impairment in older emergency department patients. Acad Emerg Med. 2005;12(7):612-6. PMID: 15995092; https://doi.org/10.1197/j.aem.2005.01.017.

28. Buschke H, Kuslansky G, Katz M, et al. Screening for dementia with the memory impairment screen. Neurology. 1999;52(2):231-8. PMID: 9932936; https://doi.org/10.1212/wnl.52.2.231.

29. Cordell CB, Borson S, Boustani M, et al. Alzheimer's Association recommendations for operationalizing the detection of cognitive impairment during the Medicare Annual Wellness Visit in a primary care setting. Alzheimers Dement. 2013;9(2):141-50. PMID: 23265826; https://doi.org/10.1016/j.jalz.2012.09.011.

30. Petrillo SL. Avaliação do desempenho do Teste de Rastreio "Memory Impairment Screen" para Demência na Doença de Alzheimer [dissertation]. Botucatu: UNESP. Faculdade de Medicina; 2017. Available from: https:// repositorio.unesp.br/handle/11449/152273. Accessed in 2021 (Mar 25).

31. Nasreddine ZS, Phillips NA, Bédirian V, et al. The Montreal Cognitive Assessment, MoCA: a brief screening tool for mild cognitive impairment. J Am Geriatr Soc. 2005;53(4):695-9. PMID: 15817019; https://doi. org/10.1111/j.1532-5415.2005.53221.x. Erratum in: J Am Geriatr Soc. 2019 Sep;67(9):1991.

32. Cesar KG, Yassuda MS, Porto FHG, Brucki SMD, Nitrini R. MoCA Test: normative and diagnostic accuracy data for seniors with heterogeneous educational levels in Brazil. Arq Neuropsiquiatr. 2019;77(11):775-81. PMID: 31826133; https://doi.org/10.1590/0004-282X20190130.

33. Cecato JF, Montiel JM, Bartholomeu D, Martinelli JE. Poder preditivo do MoCa na avaliação neuropsicológica de pacientes com diagnóstico de demência. Rev Bras Geriatr Gerontol. 2015;17(4):707-19. https://doi. org/10.1590/1809-9823.2014.13123.

34. Folstein MF, Folstein SE, McHugh PR. "Mini-mental state". A practical method for grading the cognitive state of patients for the clinician. J Psychiatr Res. 1975;12(3):189-98. PMID: 1202204; https://doi. org/10.1016/0022-3956(75)90026-6.

35. Paradela EM, Lopes C de S, Lourenço RA. Adaptação para o português do Cambridge Cognitive Examination-Revised aplicado em um ambulatório público de geriatria [Portuguese adaptation of the Cambridge Cognitive Examination-Revised in a public geriatric outpatient clinic]. Cad Saude Publica. 2009;25(12):2562-70. PMID: 20191148; https://doi.org/10.1590/ s0102-311×2009001200004. Erratum in: Cad Saude Publica. 2010 Apr;26(4):845-6.

36. Isaacs B, Akhtar AJ. The set test: a rapid test of mental function in old people. Age Ageing. 1972;1(4):222-6. PMID: 4669878; https://doi. org/10.1093/ageing/1.4.222.

37. Pfeffer RI, Kurosaki TT, Harrah CH Jr, Chance JM, Filos S. Measurement of functional activities in older adults in the community. J Gerontol.
1982;37(3):323-9. PMID: 7069156; https://doi.org/10.1093/ geronj/37.3.323.

38. Sobreira E, Pena-Pereira MA, Eckeli AL, et al. Screening of cognitive impairment in patients with Parkinson's disease: diagnostic validity of the Brazilian versions of the Montreal Cognitive Assessment and the Addenbrooke's Cognitive Examination-Revised. Arq Neuropsiquiatr. 2015;73(11):929-33. PMID: 26517216; https://doi.org/10.1590/0004$282 \times 20150156$

39. Burkart M, Heun R. Psychometric analysis of the selective reminding procedure in a sample from the general elderly population. Dement Geriatr Cogn Disord. 2000;11(2):74-80. PMID: 10705164; https://doi. org/10.1159/000017218.

40. Buschke H, Fuld PA. Evaluating storage, retention, and retrieval in disordered memory and learning. Neurology. 1974;24(11):1019-25. PMID: 4473151; https://doi.org/10.1212/wnl.24.11.1019.

41. Fuld PA. Guaranteed stimulus-processing in the evaluation of memory and learning. Cortex. 1980;16(2):255-71. PMID: 7471766; https://doi. org/10.1016/s0010-9452(80)80061-X..

42. Avila R, Lopes MA, Nakano EY, Bottino CM. Normative data of Fuld Object Memory Evaluation test for Brazilian elderly population. Arq Neuropsiquiatr. 2016;74(2):138-44. PMID: 26690838; https://doi. org/10.1590/0004-282X20150200.

43. Memória CM, Yassuda MS, Nakano EY, Forlenza OV. Brief screening for mild cognitive impairment: validation of the Brazilian version of the Montreal cognitive assessment. Int J Geriatr Psychiatry. 2013;28(1):3440. PMID: 22368034; https://doi.org/10.1002/gps.3787.

44. Rait $G$, Fletcher A, Smeeth $L$, et al. Prevalence of cognitive impairment: results from the MRC trial of assessment and management of older people in the community. Age Ageing. 2005;34(3):242-8. PMID: 15863409; https://doi.org/10.1093/ageing/afi039.

45. Brucki SMD, Nitrini R. Mini-Mental State Examination among lower educational levels and illiterates: Transcultural evaluation. Dement Neuropsychol. 2010;4(2):120-5. PMID: 29213674; https://doi.org/10.1590/ S1980-57642010DN40200008.

46. de Melo DM, Barbosa AJ. O uso do Mini-Exame do Estado Mental em pesquisas com idosos no Brasil: uma revisão sistemática [Use of the Mini-Mental State Examination in research on the elderly in Brazil: a systematic review]. Cien Saude Colet. 2015;20(12):3865-76. PMID: 26691810; https://doi.org/10.1590/1413-812320152012.06032015.

47. Mota MMPE, Banhato EFC, Silva KCA, Cupertino APFB. Triagem cognitiva: comparações entre o mini-mental e o teste de trilhas. Estud Psicol. 2008;25(3):353-9. http://dx.doi.org/10.1590/S0103-166X2008000300004.

48. Pangman VC, Sloan J, Guse L. An examination of psychometric properties of the mini-mental state examination and the standardized minimental state examination: implications for clinical practice. Appl Nurs Res. 2000;13(4):209-13. PMID: 11078787; https://doi.org/10.1053/ apnr.2000.9231.

49. Aprahamian I, Rasslan Z. Rastreio cognitivo em idosos para o clínico. Rev Soc Bras Clín Méd. 2008;6(6):254-9. 
50. Nitrini R, Lefèvre BH, Mathias SC, Caramelli P, Carrilho PEM, Sauaia N, et al. Testes neuropsicológicos de aplicação simples para o diagnóstico de demência. Arq Neuropsiquiatr. 1994;52(4):457-65. https://doi. org/10.1590/S0004-282X1994000400001.

51. Bertolucci PH, Okamoto IH, Brucki SM, et al. Applicability of the CERAD neuropsychological battery to Brazilian elderly. Arq Neuropsiquiatr. 2001;59(3-A):532-6. PMID: 11588630; https://doi.org/10.1590/s0004$282 \times 2001000400009$.

52. Rodrigues AB, Yamashita ET, Chiappetta ALML. Teste de fluência verbal no adulto e no idoso: verificação da aprendizagem verbal. Rev CEFAC. 2008;10(4):443-51. https://doi.org/10.1590/S151618462008000400004.

53. Jiang $C, X u Y$. The association between mild cognitive impairment and doing housework. Aging Ment Health. 2014;18(2):212-6. PMID: 23919266; https://doi.org/10.1080/13607863.2013.823376.

54. Jorm AF, Broe GA, Creasey $\mathrm{H}$, et al. Further data on the validity of the informant questionnaire on cognitive decline in the elderly (IQCODE). Int J Geriatr Psychiatry. 1996;1 1(2):131-9. https://doi.org/10.1002/(SICI)10991166(199602)11:2\%3C131::AID-GPS294\%3E3.0.CO;2-5.

55. Morales JM, Bermejo F, Romero M, Del-Ser T. Screening of dementia in community-dwelling elderly through informant report. Int J Geriatr Psychiatry. 1997;12(8):808-16. PMID: 9283925.

56. Morris JC. The Clinical Dementia Rating (CDR): current version and scoring rules. Neurology. 1993;43(11):2412-4. PMID: 8232972; https:// doi.org/10.1212/wnl.43.11.2412-a.

57. Montaño MB, Ramos LR. Validade da versão em português da Clinical Dementia Rating [Validity of the Portuguese version of Clinical Dementia Rating]. Rev Saude Publica. 2005;39(6):912-7. PMID: 16341400; https:// doi.org/10.1590/s0034-89102005000600007.

58. Stella F, Radanovic M, Canineu PR, de Paula VJ, Forlenza OV. Antidementia medications: current prescriptions in clinical practice and new agents in progress. Ther Adv Drug Saf. 2015;6(4):151-65. PMID: 26301069; https://doi.org/10.1177/2042098615592116.

59. Perry W, Lacritz L, Roebuck-Spencer T, et al. Population Health Solutions for Assessing Cognitive Impairment in Geriatric Patients. Clin Neuropsychol. 2018;32(7):1193-225. PMID: 30396329; https://doi. org/10.1080/13854046.2018.1517503.

60. Wray LO, Wade M, Beehler GP, Hershey LA, Vair CL. A program to improve detection of undiagnosed dementia in primary care and its association with healthcare utilization. Am J Geriatr Psychiatry. 2014;22(11):1282-91. PMID: 23954037; https://doi.org/10.1016/j.jagp.2013.04.018.

61. César KG, Brucki SM, Takada LT, et al. Prevalence of Cognitive Impairment Without Dementia and Dementia in Tremembé, Brazil. Alzheimer Dis Assoc Disord. 2016;30(3):264-71. PMID: 26629676; https://doi. org/10.1097/WAD.0000000000000122.

62. Tatsch MF, Bottino CM, Azevedo D, et al. Neuropsychiatric symptoms in Alzheimer disease and cognitively impaired, nondemented elderly from a community-based sample in Brazil: prevalence and relationship with dementia severity. Am J Geriatr Psychiatry.
2006;14(5):438-45. PMID: 16670248; https://doi.org/10.1097/01. JGP.0000218218.47279.db.

63. Laks J, Batista EM, Guilherme ER, et al. Prevalence of cognitive and functional impairment in community-dwelling elderly: importance of evaluating activities of daily living. Arq Neuropsiquiatr. 2005;63(2A):207-12. PMID: 16100963; https://doi.org/10.1590/s0004$282 \times 2005000200003$.

64. Jeong SK, Cho KH, Kim JM. The usefulness of the Korean version of modified Mini-Mental State Examination (K-mMMSE) for dementia screening in community dwelling elderly people. BMC Public Health. 2004;4:31. PMID: 15283869; https://doi.org/10.1186/1471-2458-4-31.

65. de Silva HA, Gunatilake SB. Mini Mental State Examination in Sinhalese: a sensitive test to screen for dementia in Sri Lanka. Int J Geriatr Psychiatry. 2002;17(2):134-9. PMID: 11813275; https://doi.org/10.1002/gps.541.

66. Dartigues JF, Commenges D, Letenneur D, et al. Cognitive predictors of dementia in elderly community residents. Neuroepidemiology. 1997;16(1):29-39. PMID: 8994938; https://doi.org/10.1159/000109668.

67. Macías Ortega MM, Paguada Canales E, Maradiaga E, Sierra M, Hesse H, Navarro E, et al. Prevalencia de demencia y factores asociados en adultos mayores, Aldea Tablones Arriba, Municipio de Yusguare, Choluteca, mayo 2010 - 2011. Rev Fac Cienc Méd. 2012;9(1):27-33.

68. Han JW, Kim TH, Kwak KP, et al. Overview of the Korean Longitudinal Study on Cognitive Aging and Dementia. Psychiatry Investig. 2018;15(8):76774. PMID: 30086611; https://doi.org/10.30773/pi.2018.06.02.

69. Beato RG, Nitrini R, Formigoni AP, Caramelli P. Brazilian version of the Frontal Assessment Battery (FAB): Preliminary data on administration to healthy elderly. Dement Neuropsychol. 2007;1 (1):59-65. PMID: 29213369; https://doi.org/10.1590/S1980-57642008DN10100010.

70. Segabinazi JD, Junior SD, Salles JF De. Teste de Retenção Visual de Benton: apresentação do manual brasileiro. Avaliação Psicológica. 2013;12(3):429-32. Available from: http://pepsic.bvsalud.org/pdf/avp/ v12n3/v12n3a18.pdf. Accessed in 2021 (Mar 25).

71. Sabbagh MN, Malek-Ahmadi M, Kataria R, et al. The Alzheimer's questionnaire: a proof of concept study for a new informant-based dementia assessment. J Alzheimers Dis. 2010;22(3):1015-21. PMID: 20930293; https://doi.org/10.3233/JAD-2010-101185.

72. Choe JY, Youn JC, Park JH, et al. The Severe Cognitive Impairment Rating Scale--an instrument for the assessment of cognition in moderate to severe dementia patients. Dement Geriatr Cogn Disord. 2008;25(4):321-8. PMID: 18319591; https://doi.org/10.1159/000119124.

Authors' contributions: Feichtenberger PRP: conceived and designed the study, performed the review, analyzed the data and wrote the manuscript; Laureano-Rocha MR: conceived and designed the study, performed the review, analyzed the data and did writing-review and editing of the manuscript; Puga MES: conceived and designed the experiments, performed the review, analyzed the data and did writingreview of the manuscript; Martinez JE: conceived and designed the experiments, performed the review, analyzed the data and did writing- 
review and editing of the manuscript. All authors actively contributed to discussion of the results from the study, and reviewed and approved the final version to be released

Presentation of the work: October 23, 2020, in defense of the master's dissertation of Patrícia Regina Piedade Feichtenberger

Acknowledgments: The authors acknowledge the assistance of Thanye Caroline de Oliveira Medeiros, psychology student, for organizing all the 983 articles surveyed; and also Isabel Cristina Campos Feitosa and Vera Lucia de Jesus Mescoki for conducting the search strategy in databases at Pontifícia Universidade Católica de São Paulo, Brazil

Sources of funding: None

Conflict of interest: The authors declare that they did not have any

conflict of interest

Date of first submission: October 22, 2020

Last received: October 22, 2020

Accepted: March 15, 2021

\section{Address for correspondence:}

Patrícia Regina Piedade Feichtenberger

Pontifícia Universidade Católica de São Paulo (PUC-SP)

R. Joubert Wey, 290

Sorocaba (SP) — Brasil

CEP 18030-070

Tel. (+55 15) 3212-9878

E-mail: prpfeichtenberger@hotmail.com 